\title{
Characterization of combustion synthesized zirconia powder by UV-vis, IR and other techniques
}

\author{
H RANJAN SAHU and G RANGA RAO* \\ Department of Chemistry, Indian Institute of Technology, Chennai 600 036, India
}

MS received 31 March 2000; revised 25 June 2000

\begin{abstract}
Fine powders of zirconia were prepared by employing combustion method with varying fuel to precursor molar ratios. The zirconia powders contained more amount of monoclinic phase as the fuel content was increased. This aspect was studied using XRD, IR and UV-vis diffuse reflectance techniques. The surface acidbase properties of these samples were also investigated by indicator titration method. The catalytic activity was probed with transfer hydrogenation reaction in liquid phase. It was found that combustion synthesized zirconia did not provide required active sites for transfer hydrogenation reactions in liquid phase unlike hydrous zirconia.
\end{abstract}

Keywords. Combustion synthesis; $\mathrm{ZrO}_{2}$; UV-vis; XRD; catalysis.

\section{Introduction}

Application of zirconium dioxide has been quite promising in catalysis and many other areas due to its versatile structural and surface chemical properties as well as good thermal stability (Mercera et al 1990; Yamaguchi 1994; Hattori 1995; Scheithauer et al 1998; Somiya and Akiba 1999). It has been reported as a better catalyst and catalyst support compared to classical materials such as $\mathrm{Al}_{2} \mathrm{O}_{3}, \mathrm{SiO}_{2}$ and $\mathrm{TiO}_{2}$ (Mercera et al 1990; Yamaguchi 1994; Hattori 1995; Song and Sayari 1996; Scheithauer et al 1998). The modified versions of zirconium dioxide, viz. the sulfated $\mathrm{ZrO}_{2}$, zirconia substituted mixed oxides such as $\mathrm{Ce}_{x} \mathrm{Zr}_{1-x} \mathrm{O}_{2}$ solid solutions $(0 \leq x \leq 1)$, various transition metal stabilized zirconia and hydrous zirconium oxide have been reported to be effective for several organic reactions, combustion and gas phase reactions (Choudhary et al 1996; Song and Sayari 1996; Aramendia et al 1997; Upadhya et al 1997; Fornasiero et al 1998; Kaspar et al 1999; Ranga Rao 1999). The partial substitution of $\mathrm{ZrO}_{2}$ into $\mathrm{CeO}_{2}$ improves the thermal stability, oxygen storage capacity and redox properties of ceria considerably. This is considered as a significant contribution to three-way catalyst (TWC) technology (Ranga Rao et al 1995; Fornasiero et al 1998; Kaspar et al 1999). However, the role of $\mathrm{ZrO}_{2}$ in $\mathrm{CeO}_{2}-\mathrm{ZrO}_{2}$ mixed oxide catalysts seems to be elusive. The catalytic activity of $\mathrm{ZrO}_{2}$ as a single oxide is attributed to the bi-functional acid-base properties, the oxidizing and reducing properties and the terminal and bridged surface $\mathrm{OH}$ groups. The catalytic performance of zirconium dioxide depends also

\footnotetext{
*Author for correspondence
}

on the structural, textural properties, surface area, synthesis method adopted and calcination temperatures (Yamaguchi 1994; Aramendia et al 1997).

Several procedures have been developed using number of precursor salts to prepare pure zirconia of desired phase formations and strong acid-base sites and surface areas (Srinivasan and Davis 1992; Arul Dhas and Patil 1994; Keshavaraja and Ramaswamy 1994; Nakabayashi 1996; Aramendia et al 1997; Calafat 1998; Rossignol et al 1999). Recently, the surface areas of zirconia and sulfated zirconia have been expanded employing surfactant template methods (Sudhakar Reddy and Sayari 1996; Kim et al 1997). The present study describes synthesis of nanocrystalline zirconia using combustion method and its bulk and surface characterization employing various techniques. The combustion approach is quite simple and quick to obtain fine particles of mono and multicomponent oxides that can be used as supports as well as catalyst materials (Aruna and Patil 1998; Terribile et al 1998). It is also a versatile method to synthesize fine support oxide with dispersed catalyst precursor in a single step. The method has been employed recently to synthesize homogeneous, and fine crystalline $\mathrm{Cu} / \mathrm{CeO}_{2}$ and Pd/alumina catalysts (Bera et al 1999; Greca et al 1999). There is a wide scope of using this method to produce other oxide materials with required properties for catalysis.

\section{Experimental}

\section{$2.1 \mathrm{ZrO}_{2}$ preparation}

The fine zirconium dioxide powder material is synthesized using zirconyl nitrate, $\mathrm{ZrO}\left(\mathrm{NO}_{3}\right)_{2} \cdot 2 \mathrm{H}_{2} \mathrm{O}$, as precursor salt and carbohydrazide, $\mathrm{N}_{2} \mathrm{H}_{3} \mathrm{CON}_{2} \mathrm{H}_{3}$, as fuel 
(Arul Dhas and Patil 1994). Water of hydration of the precursor salt is determined using TG/DT analysis. Carbohydrazide is prepared by hydrazinolysis of diethylcarbonate as reported in the literature (Mohr et al 1953). In a typical batch preparation, $5.0 \mathrm{~g}$ of zirconyl nitrate and $1.75 \mathrm{~g}$ of carbohydrazide are dissolved in minimum amount of water and the mixture is kept in a furnace preheated to $350^{\circ} \mathrm{C}$. The mixture instantaneously gets ignited producing a foamy material of homogeneous zirconium oxide, simultaneously releasing gaseous products. Several zirconium oxide samples are prepared by changing the molar ratio of zirconyl nitrate and carbohydrazide. The samples are coded according to the precursor to fuel molar ratio $1: 1 \cdot 00,1: 1 \cdot 25,1: 1.75$ and $1: 2.25$ as $\mathrm{Zr}$ $100, \mathrm{Zr}-125, \mathrm{Zr}-175$ and $\mathrm{Zr}-225$, respectively. Hydrous zirconium oxide is also prepared for comparison following the method (Aramendia et al 1997) and coded as HZr-500.

\subsection{Characterization}

The zirconia samples have been characterized using powder XRD (Philips PW 1710 using $\mathrm{MoK}_{\alpha}$ radiation), UV-Diffuse reflectance (Varian 5E UV-vis-NIR spectrophotometer with $\mathrm{BaSO}_{4}$ coated integration sphere) and IR (Shimadzu IR-470). We have calculated the crystallite size using the classical Scherrer formula

$$
D=\frac{K \lambda}{\beta \cos \theta},
$$

where $D$ is the average crystallite size, $K=1, \lambda=$ $0.7093 \AA$ for $\mathrm{MoK}_{\alpha}, \beta$ the peak width and $\theta$ the peak angle. The Scherrer formula indicates that $\mathrm{MoK}_{\alpha}$ radiation is useful in obtaining diffraction pattern from smaller crystallites because of smaller wavelength and the diffraction occurring at lower angles. The line broadening is effectively reduced. For UV-vis measurements, a pellet of $0.1 \mathrm{~g}$ of zirconia is used to record UV-vis diffuse reflectance spectra in the wavelength region 200-2000 nm. PTFE has been used as reference material. The SchusterKubelka-Munk (SKM) function for scattering is expressed as

$$
F\left(R_{\infty}\right)=\left(1-R_{\infty}\right)^{2} / 2 R_{\infty}=K / S,
$$

where $R_{\infty}$ is the reflectance of the infinitely thick solid sample, $K$ and $S$ are the absorption and scattering coefficients. The optical diffuse reflection spectra are presented here as $F\left(R_{\infty}\right)$ vs wavelength of the light in the UV-vis region (Schoonheydt 1984). The IR spectra of zirconia are recorded using $\mathrm{KBr}$ pellets. Surface areas of powder samples have been measured using CE instruments Sorptomatic model 1990.

\subsection{Surface acidity and basicity determination}

The total surface acidity and basicity of all the zirconia samples have been determined by simple back-titration methods (Karuppannasamy 1980; Sugunan and Varghese 1998). A $0.025 \mathrm{M}$ solution of trichloroacetic acid in dry benzene is used for estimation. The catalyst weighing $0.5 \mathrm{~g}$ is suspended in the acid solution for $24 \mathrm{~h}$ and the excess acid is titrated against $n$-butylamine using neutral red as an indicator. This gives the total surface acidity of the zirconia sample. Similarly, the catalyst sample is suspended in $n$-butylamine for $24 \mathrm{~h}$ and the excess base is estimated by titrating it against trichloroacetic acid to obtain the total surface basicity.

\subsection{Catalytic activity test}

Transfer hydrogenation of cyclohexanone with isopropyl alcohol as the hydrogen donor is carried out to test the catalytic activity of the zirconia samples. This reaction is reported to be efficiently catalyzed by hydrous zirconium oxide (Shibagaki et al 1988). The solution containing $1.0 \mathrm{ml}$ of cyclohexanone and $20 \mathrm{ml}$ of isopropyl alcohol is refluxed at $80^{\circ} \mathrm{C}$ for $24 \mathrm{~h}$ after adding $0 \cdot 10 \mathrm{~g}$ of zirconium oxide catalyst. The catalyst is separated and the product conversion is obtained by gas chromatographic analysis (NUCON 5890) employing 10\% carbowax column.

\section{Results}

\section{$3.1 X R D$}

The combustion reaction between the redox mixture of carbohydrazide and zirconyl nitrate giving zirconium oxide can be written as follows:

$$
\begin{aligned}
\mathbf{p Z r O}\left(\mathrm{NO}_{3}\right)_{2} & +\mathbf{q} \mathrm{CH}_{6} \mathrm{~N}_{4} \mathrm{O}+\mathbf{t} \mathrm{O}_{2} \rightarrow \mathbf{p} \mathrm{ZrO}_{2}(s) \\
& +\mathbf{q C O} \mathrm{CO}_{2}(g)+\mathbf{r} \mathrm{H}_{2} \mathrm{O}(g)+\mathbf{s N}_{2}(g),
\end{aligned}
$$

where $\mathbf{p}$ through $\mathbf{t}$ represents the stoichiometric numbers of reactants and products involved for each $\mathrm{C} / \mathrm{Z}$ molar ratio (table 1). Figure 1 shows the powder X-ray diffraction pattern of zirconium oxide samples prepared by varying the fuel to precursor molar ratios as presented in table 1. When equimolar amounts are used, XRD result shows only the characteristic reflections for metastable tetragonal zirconia phase (figure 1a). As the amount of fuel is increased from $\mathrm{Zr}-100$ to $\mathrm{Zr}-225$, there is a gradual change in crystal structures from the metastable tetragonal $\mathrm{ZrO}_{2}(\mathrm{mt})$ to the stable monoclinic $(\mathrm{m})$ phase (figure 1). The corresponding percentage increase in monoclinic phase is summarized in table 1 . The amount of monoclinic phase present in the zirconia is estimated following the method using the expression (Calafat 1998),

$$
\% M_{\text {monoclinic }}=\frac{\sum M_{\text {monoclinic }} \times 100}{T_{\text {tetragonal }}+\sum M_{\text {monoclinic }}},
$$


Table 1. Reaction parameters and phases formed in the combustion synthesis of zirconia.

\begin{tabular}{|c|c|c|c|c|c|c|c|c|c|c|c|}
\hline \multirow[b]{2}{*}{ Sample } & \multirow[b]{2}{*}{$\mathrm{C} / \mathrm{Z}^{\S}$} & \multicolumn{5}{|c|}{ Reaction stoichiometry } & \multirow{2}{*}{$\begin{array}{c}\Delta H_{\mathrm{r}}^{0} \\
(\mathrm{STP}) \\
(\mathrm{Kcal} / \mathrm{mol})\end{array}$} & \multicolumn{2}{|c|}{$T_{\text {ad }}\left({ }^{\circ} \mathrm{C}\right)$} & \multirow[b]{2}{*}{ Phase } & \multirow{2}{*}{$\begin{array}{c}\% \\
\text { Monoclinic }\end{array}$} \\
\hline & & $p$ & $q$ & $r$ & $s$ & $t$ & & Experimental $^{\dagger}$ & Calculated & & \\
\hline $\mathrm{Zr}-100$ & $1 \cdot 00$ & 4 & 4 & 20 & 12 & $2 *$ & $-789 \cdot 5$ & - & $1072 \cdot 6$ & $\mathrm{mt}$ & 0 \\
\hline Zr-125 & $1 \cdot 25$ & 4 & 5 & 23 & 14 & 0 & $-1064 \cdot 5$ & $1100 \pm 100$ & $1316 \cdot 9$ & $m t+m$ & 58 \\
\hline Zr-175 & $1 \cdot 75$ & 4 & 7 & 29 & 18 & 4 & $-1614 \cdot 6$ & - & $1612 \cdot 5$ & $m t+m$ & 76 \\
\hline Zr-225 & $2 \cdot 25$ & 4 & 9 & 35 & 22 & 8 & $-2164 \cdot 7$ & $1400 \pm 100$ & $1807 \cdot 0$ & $m t+m$ & 85 \\
\hline
\end{tabular}

*Oxygen released during combustion; ${ }^{\dagger}$ From Arul Dhas and Patil (1994);

$\mathrm{m}=$ monoclinic $; \mathrm{mt}=$ metastable tetragonal;

${ }^{\S} \mathrm{C} / \mathrm{Z}=$ carbohydrazide/zirconyl nitrate mole ratio.

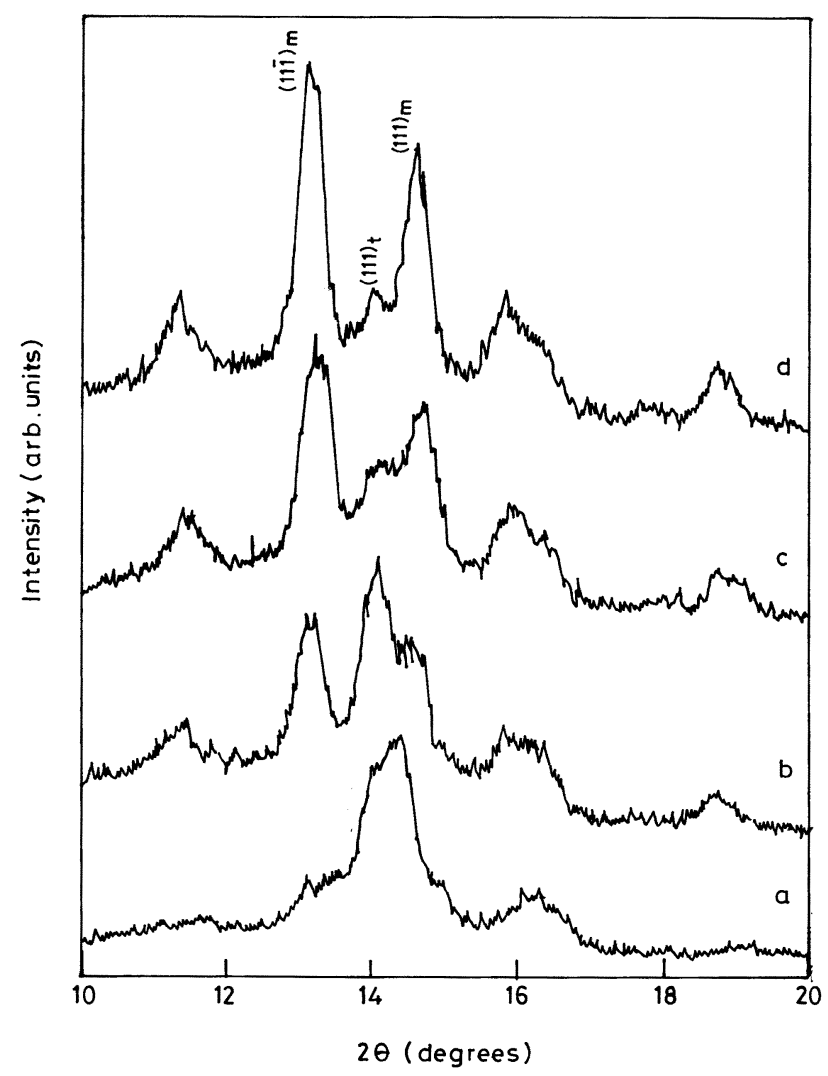

Figure 1. X-ray diffraction pattern for combustion synthesized zirconium oxides using various precursor to fuel mole ratios: a. $1: 1 \cdot 00$, b. $1: 1 \cdot 25$, c. $1: 1 \cdot 75$ and d. $1: 2 \cdot 25$.

where $\Sigma M_{\text {monoclinic }}$ is the sum of the areas under the diffraction peaks from the $(11 \overline{1})$ and (111) planes of the monoclinic phase and $T_{\text {tetragonal }}$ stands for the area under (111) plane of tetragonal phase. These areas have been obtained using Gaussian curve fitting.

The surface areas and crystallite sizes of zirconia powders prepared using combustion synthesis are summarized in table 2. The powders contain nanostructured crystallites of size in the range $5-15 \mathrm{~nm}$. The crystallite size of monoclinic phase increases while that of the tetragonal phase decreases when fuel ratio is increased. This indicates that the monoclinic crystallites grow at the expense of tetra-
Table 2. Surface area and crystallite size data for combustion synthesized zirconia powders.

\begin{tabular}{llccc}
\hline & & \multirow{2}{*}{$\begin{array}{c}\text { Surface } \\
\text { area }\end{array}$} & \multicolumn{2}{c}{ Crystallite size $(\AA)$} \\
\cline { 3 - 4 } Sample & $\mathrm{C} / \mathrm{Z}^{\S}$ & $\left(\mathrm{m}^{2} / \mathrm{g}\right)$ & $(111)_{\text {tetragonal }}$ & $(11 \overline{1})_{\text {monoclinic }}$ \\
\hline $\mathrm{Zr}-100$ & 1 & 15 & $54 \cdot 18$ & - \\
$\mathrm{Zr}-125$ & $1 \cdot 25$ & 11 & $149 \cdot 00$ & $80 \cdot 99$ \\
$\mathrm{Zr}-175$ & 1.75 & 23 & $76 \cdot 02$ & $88 \cdot 34$ \\
$\mathrm{Zr}-225$ & $2 \cdot 25$ & 22 & $62 \cdot 71$ & $105 \cdot 98$ \\
\hline
\end{tabular}

${ }^{\S} \mathrm{C} / \mathrm{Z}=$ carbohydrazide/zirconyl nitrate mole ratio.

gonal crystallites as a function of fuel ratio. It is also observed that the overall surface area of the powder samples increased moderately with fuel content.

\subsection{IR and $U V$-vis diffuse reflectance}

The IR spectra of all zirconia samples prepared by the combustion method are presented in figure 2 . The IR spectra of zirconia samples essentially show the various stretching frequencies at $445 \mathrm{~cm}^{-1}$ and $410 \mathrm{~cm}^{-1}$ (doublet), $500 \mathrm{~cm}^{-1}, 572 \mathrm{~cm}^{-1}, 740 \mathrm{~cm}^{-1}, 1104 \mathrm{~cm}^{-1}$ and $1187 \mathrm{~cm}^{-1}$ respectively as reported earlier (Powers and Gray 1973). The features particularly at $740 \mathrm{~cm}^{-1}$ and $500 \mathrm{~cm}^{-1}$, due to $\mathrm{Zr}-\mathrm{O}_{2}-\mathrm{Zr}$ asymmetric and $\mathrm{Zr}-\mathrm{O}$ stretching modes respectively, confirm the formation of $\mathrm{ZrO}_{2}$ phases. There is a strong additional feature observed around $1380 \mathrm{~cm}^{-1}$ when the fuel content is relatively less. This feature almost disappears as the fuel content is increased. This may be due to carbonate related signature (Trovarelli 1996). The broad feature around $1632 \mathrm{~cm}^{-1}$ seems to occur due to adsorbed water deformation mode.

Zirconium oxide is a direct band gap insulator with two direct band-to-band transitions at 5.2 and $5.79 \mathrm{eV}(238$ and $214 \mathrm{~nm}$ respectively) (Emeline et al 1998; Scheithauer et al 1998). The onset of the linear increase in the diffuse reflectance spectrum is taken as a measure of the forbidden gap that occurs at around $240 \mathrm{~nm}(5 \cdot 17 \mathrm{eV})$. This is a characteristic of the edge position of the bulk tetragonal zirconia phase (Scheithauer et al 1998). The 
typical diffuse reflectance spectrum for one of the catalysts (Zr-225) is shown in figure 3. A broad reflectance maximum $F\left(R_{\infty}\right)_{\max }$ seems to occur around $214 \mathrm{~nm}$ which can be recognized as the interband transition in the monoclinic zirconium oxide (Aita and Kin 1990). The variation in the $F\left(R_{\infty}\right)_{\max }$ at this position against the percentage composition of the monoclinic phase in various samples is given in table 3 . It shows an interesting correlation that the $F\left(R_{\infty}\right)_{\max }$ decreases as the percentage composition of the monoclinic phase increases.

\subsection{Indicator titration for surface acidity-basicity}

The results of the indicator acid/base titration are compiled in table 4 . We have also included the results of hydrous zirconia (HZr-500) in the table. The data shows that the hydrous zirconia has maximum number of acidic as well as basic sites as compared to the combustion synthesized zirconia samples. By and large, the zirconia samples show higher number of acidic sites than the basic sites.

\subsection{Catalytic activity}

The catalytic activity of all catalysts towards transfer hydrogenation of ketone revealed that only hydrous zirconia $(\mathrm{HZr}-500)$ is active enough to carry out a total conver-

Table 3. Correlation between the $F\left(R_{\infty}\right)_{\max }$ and percentage monoclinic phase of various zirconia samples.

\begin{tabular}{lccc}
\hline Sample & $F\left(R_{\infty}\right)_{\max }$ & Phase & \% Monoclinic \\
\hline HZr-500 & $0 \cdot 5$ & Amorphous & - \\
Zr-100 & $3 \cdot 5$ & $\mathrm{mt}$ & 0 \\
Zr-125 & $2 \cdot 5$ & $\mathrm{mt}+\mathrm{m}$ & 58 \\
Zr-175 & $1 \cdot 5$ & $\mathrm{mt}+\mathrm{m}$ & 76 \\
Zr-225 & $1 \cdot 5$ & $\mathrm{mt}+\mathrm{m}$ & 86 \\
\hline
\end{tabular}

$\mathrm{m}=$ monoclinic $; \mathrm{mt}=$ metastable tetragonal

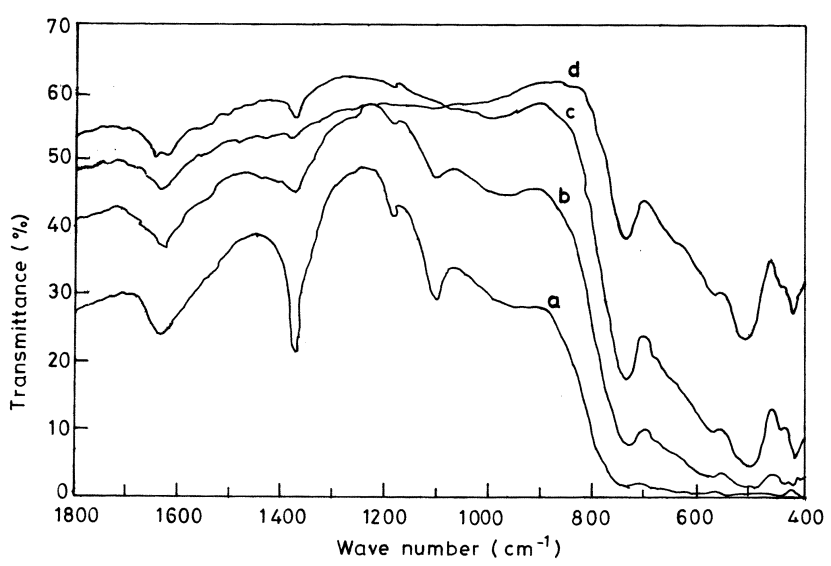

Figure 2. IR spectra of combustion synthesized zirconium oxides as mentioned in figure 1 . sion of the cyclohexanone to cyclohexanol where zirconia prepared by combustion method showed no activity. The reason why hydrous zirconia is catalytically active is still not clear (Hattori 1995). The present study indicates that the presence of relatively large number of acid sites could be responsible for hydrous zirconia to be active over combustion synthesized zirconia. There is also a clear indication that combustion synthesis destroys the active sites rendering it to be inactive for transfer hydrogenation reactions in liquid phase.

\section{Discussion}

Zirconia exists in tetragonal $\left(\beta-\mathrm{ZrO}_{2}\right)$, monoclinic $(\alpha$ $\left.\mathrm{ZrO}_{2}\right)$ and cubic $\left(\gamma-\mathrm{ZrO}_{2}\right)$ phases. Among all these phases, monoclinic is more stable at ambient temperatures whereas tetragonal and cubic phases are stable at much

Table 4. Total acidity and basicity parameters estimated from titration method for zirconia sample.

\begin{tabular}{lcc}
\hline Sample & $\begin{array}{c}\text { Acidity }(\mathrm{mmol} / \mathrm{g}) \\
n \text {-butylamine } \\
\text { titration }\end{array}$ & $\begin{array}{c}\text { Basicity }(\mathrm{mmol} / \mathrm{g}) \\
\text { Trichloroacetic } \\
\text { acid titration }\end{array}$ \\
\hline $\mathrm{HZr}-500$ & $1 \cdot 160$ & $0 \cdot 3560$ \\
$\mathrm{Zr}-100$ & $0 \cdot 410$ & 0.1375 \\
$\mathrm{Zr}-125$ & $0 \cdot 470$ & 0.2625 \\
$\mathrm{Zr}-175$ & $0 \cdot 110$ & 0.0125 \\
$\mathrm{Zr}-225$ & $0 \cdot 446$ & 0.0750 \\
\hline
\end{tabular}

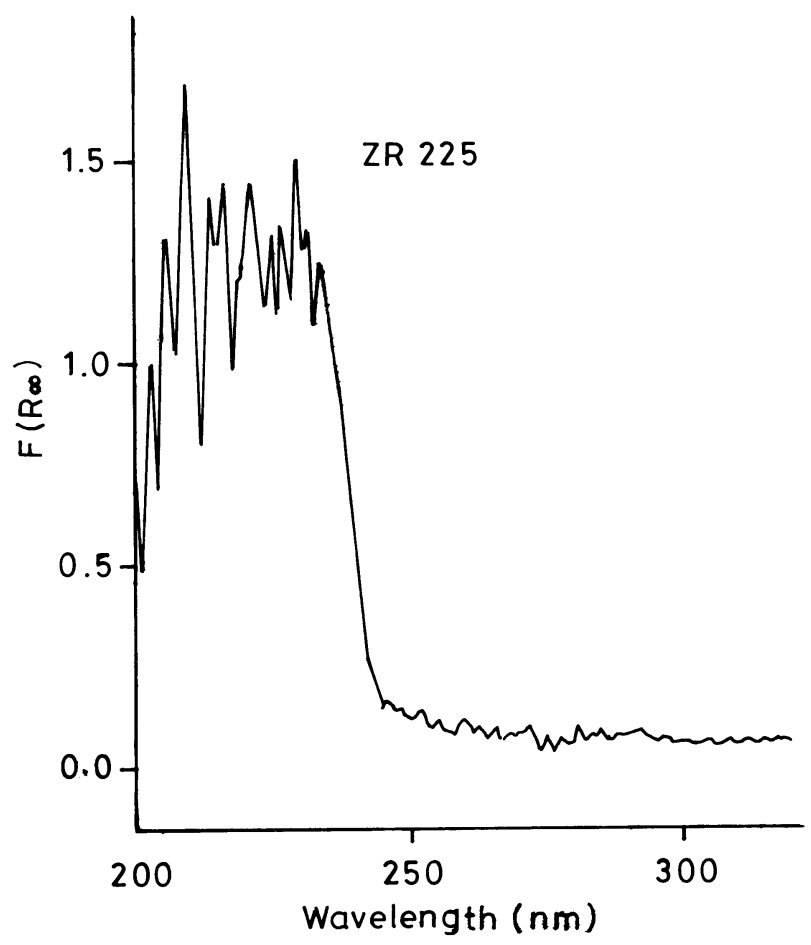

Figure 3. Typical UV-vis diffuse reflectance spectrum for Zr225 sample. 
higher temperatures (Yamaguchi 1994; Emeline et al 1998). It also exists in metastable tetragonal phase up to about $650^{\circ} \mathrm{C}$. It is believed that the metastable tetragonal phase is stabilized due to impurities and crystallite size. However, the gradual phase change from metastable tetragonal to monoclinic ( $\mathrm{mt} \rightarrow \mathrm{m}$ ) has been observed in this study as well as previously by Arul Dhas and Patil (1994). This transition has been ascribed to higher flame temperatures resulting from the presence of excess of fuel in the reaction mixture. High temperatures are usually generated during the decomposition of $\mathrm{CH}_{6} \mathrm{~N}_{4} \mathrm{O}$ fuel which is an exothermic process $\left(\Delta H_{\mathrm{f}}=+31.79 \mathrm{~kJ} / \mathrm{mol}\right)$. Flame temperature of the order of $1400 \pm 100^{\circ} \mathrm{C}$ has been measured by radiation pyrometer and this temperature seems to be sufficiently high to influence the above phase transition in zirconia. Since these combustion reactions occur in shorter duration at higher temperatures, the dissipation of heat produced during combustion process would be negligible. In such a thermally isolated system, the temperature to which the product is raised can be considered as an adiabatic temperature, $T_{\text {ad }}$ (Holt and Munir 1986). The enthalpy of the reaction can be expressed as

$$
\Delta H_{298}^{0}=\int_{298}^{T_{\mathrm{ad}}} C_{\mathrm{p}}(\text { product }) \mathrm{d} T,
$$

where $\Delta H_{298}^{0}$ is the enthalpy of reaction at $298 \mathrm{~K}, C_{\mathrm{p}}$ (product) the heat capacity of the product and $T_{\mathrm{ad}}$ the adiabatic temperature to which the reaction is raised. The calculated enthalpies for combustion reactions of various stoichiometries producing different phases of zirconia are summarized in table 1 . The adiabatic temperatures $\left(T_{\mathrm{ad}}\right)$ are calculated using (2) by substituting appropriate enthalpies of reactions and heat capacities of products (West and Astle 1980). The variation of heat capacity with temperature is also considered in the calculation and the results are given in table 1 in comparison with experimental values. They are in good agreement with each other.

It is clear from the data in table 1 that the reaction enthalpies increase rapidly with fuel content in the mixture and the excess heat generated raises the adiabatic temperature as high as $1500^{\circ} \mathrm{C}$. At higher temperatures, the formation of homogeneous monoclinic phase is more favoured. Also the intensity of the vibrational feature at $740 \mathrm{~cm}^{-1}\left(\mathrm{Zr}-\mathrm{O}_{2}-\mathrm{Zr}\right.$ asymmetric mode $)$ appears to become more prominent as the monoclinic content increases in the combustion product. However there has been no direct correlation of this mode to the monoclinic zirconia phase (Powers and Gray 1973). It is evident from UV-vis and XRD data in table 3 that there is an inverse correlation between $F\left(R_{\infty}\right)_{\max }$ at $214 \mathrm{~nm}$ and the percentage monoclinic phase in the final product. The crystallite size analysis in table 2 is also quite interesting. The average sizes of the crystallites reported here are significantly less than the values reported earlier on relatively low sur- face area samples (Arul Dhas and Patil 1994). The comparison of crystallite size values of monoclinic and tetragonal phases also indicates that there is a gradual growth of monoclinic phase. These observations once again corroborate the formation of monoclinic phase in fuel rich combustion environment.

The surface acid-base properties are inherent and characteristic of many oxide materials that are important in adsorption and surface catalytic reactions. A large body of information exists in the literature concerning the surface acidity and basicity of various oxides and their quantitative determination using titration and adsorption methods. Zirconia is a unique case exhibiting both acidic and basic sites on the surface. Previous studies show that these sites on micro-crystalline zirconia prepared by wet methods are affected by the surface area and calcination temperatures (Nakabayashi 1996; Aramendia et al 1997). We have estimated the acid-base site distribution of our samples employing indicator titration method. The results in table 4 show that the hydrous zirconia (HZr-500) sample has the same order of acid-base site distribution as reported elsewhere (Nakabayashi 1996). However, combustion synthesized samples show quite low acid-base site distributions. This is understandable from the fact that the nano-crystals of zirconia formed at high temperatures tend to be highly crystalline in nature and defect free. The defects and lattice imperfection sites on the crystallite surface are known to contribute to acid-base and redox properties of oxides (Ranga Rao 1999). This is also a plausible reason for the inactivity of zirconia samples towards conversion of the cyclohexanone to cyclohexanol as mentioned above. Therefore the zirconia samples prepared by combustion method can be used as good inert supports. However, if they were to be used as catalyst materials in the liquid phase reactions, the activity of the zirconia fine powders needs to be regenerated suitably using acid-base treatments. Work in this direction is in progress. However, preliminary results indicate that combustion synthesized zirconia powder as such shows significant activity for cyclohexanone to cyclohexanol conversions under vapour phase conditions at $300^{\circ} \mathrm{C}$.

\section{Conclusions}

The following conclusions can be drawn from this study. Zirconia phase change can be achieved by changing the fuel content in the combustion mixture. Monoclinic phase formation is highly favoured at higher fuel content. A combined use of XRD, IR and UV-vis diffuse reflectance techniques conforms the formation of monoclinic phases. The surface acid-base sites are found to be an order of magnitude less compared to hydrous zirconia rendering combustion synthesized zirconia to be inactive for transfer hydrogenation reactions in liquid phase. However, this material seems to show catalytic activity for the same reaction under vapour phase conditions. 


\section{Acknowledgements}

The Council of Scientific and Industrial Research, New Delhi, is gratefully acknowledged for financial support. We thank Mr Ramesh Sistla, Physics Department, IIT Chennai, for XRD analysis.

\section{References}

Aita C R and Kin K C 1990 J. Am. Ceram. Soc. 733209

Aramendia M A, Boráu V, Jiménez C, Marinas J M, Porras A and Urbano F J 1997 J. Chem. Soc. Faraday Trans. 931431

Arul Dhas N and Patil K C 1994 Int. J. Self-Propag. HighTemp. Synth. 3311

Aruna S T and Patil K C 1998 Nanostructured Mater. 10955

Bera P, Aruna S T, Patil K C and Hegde M S 1999 J. Catal. 18636

Calafat A 1998 Stud. Surf. Sci. Catal. 118837

Choudhary V R, Uphade B S, Pataskar S G and Keshavaraja A 1996 Angew. Chem. Int. Ed. Engl. 352393

Emeline A, Cataeva G V, Litke A S, Rudakova A V, Ryabchuk V K and Serpone N 1998 Langmuir 145011

Fornasiero P, Ranga Rao G, Kaspar J, Erario F L and Graziani M 1998 J. Catal. 175269

Greca M C, Moraes C, Morelli M R and Segadaes A M 1999 Appl. Catal. A: General 17987

Hattori H 1995 Chem. Rev. 95537

Holt J B and Munir Z A 1986 J. Mater. Sci. 21251

Karuppannasamy S 1980 Mechanistic studies of reactions of phenols and alcohols over thoria, Ph.D. Thesis, Indian Institute of Technology, Madras

Kaspar J, Fornasiero P and Graziani M 1999 Catal. Today 50 285

Keshavaraja A and Ramaswamy A V 1994 J. Mater. Res. 9837
Kim A, Bruinsma P, Chen Y, Wang L-Q and Lin J 1997 Chem. Commun. 161

Mercera P D L, Van Ommen J G, Doesburg E B M, Burggraaf A J and Ross J R H 1990 Appl. Catal. 57127

Mohr E B, Berzinki J J and Audrieth L F 1953 Inorg. synth. (eds) John C Bailar, J Kleinberg, T Moeller, E G Rochow, W C Schumb and J D Scott (New York: McGraw-Hill) 4 pp 32-35

Nakabayashi H 1996 Chem. Letts 945

Powers A and Gray H B 1973 Inorg. Chem. 122721

Ranga Rao G 1999 Bull. Mater. Sci. 2289

Ranga Rao G, Fornasiero P, Kaspar J, Meriani S, Di Monte R and Graziani M 1995 Stud. Surf. Sci. Catal. 96631

Rossignol S, Madier Y and Duprez D 1999 Catal. Today 50 261

Scheithauer M, Grasselli R K and Knözinger H 1998 Langmuir 143019

Schoonheydt R A 1984 Characterization of heterogeneous catalysts (ed.) F Delannay (New York: Marcel Dekker) Ch. 4, p. 125

Shibagaki M, Takahashi K and Matsushita H 1988 Bull. Chem. Soc. Jpn 613283

Somiya S and Akiba T 1999 Bull. Mater. Sci. 22207

Song X and Sayari A 1996 Catal. Rev. Sci. Eng. 38329

Srinivasan R and Davis B H 1992 Catal. Letts 14165

Sudhakar Reddy J and Sayari Abdelhamid 1996 Catal. Letts. 38219

Sugunan S and Varghese B 1998 Indian J. Chem. A37 806

Terribile D, Trovarelli A, Llorca J, Leitenburg C and Dolcetti G 1998 Catal. Today 4379

Trovarelli A 1996 Catal. Rev. Sci. Eng. 38439

Upadhya T T, Katdare S P, Sabde D P, Ramaswamy V and Sudalai A 1997 Chem. Commun. 1119

West R C and Astle M J (eds) 1980 CRC handbook of chemistry and physics (Boca Raton, Florida: CRC Press Inc.) 61st ed., p. D-66

Yamaguchi T 1994 Catal. Today 20199 